\title{
INTEGRASI SISTEM ELEKTRONIK LOG BOOK PENANGKAPAN IKAN (ELPI) DENGAN SISTEM PEMANTAUAN KAPAL PERIKANAN (VMS) UNTUK PEMBANGUNAN PERIKANAN BERKELANJUTAN
}

\author{
INTEGRATION BETWEEN ELECTRONIC FISHING LOG BOOK SYSTEMS WITH VESSEL \\ MONITORING SYSTEM FOR SUSTAINABLE FISHERIES DEVELOPMENT
}

\author{
Hadhi Nugroho, Agus Sufyan dan Rudhy Akhwady \\ Pusat Pengkajian dan Perekayasaan Teknologi Kelautan dan Perikanan, Jl. Pasir Putih I Ancol Timur, Jakarta \\ Email: hadhinugroho@gmail.com, agussufyan@yahoo.com,dan r_akhwady@yahoo.com
}

Diterima tanggal: 7 Juni 2013, diterima setelah perbaikan: 30 Oktober 2013, disetujui tanggal: 2 Desember 2013

\begin{abstract}
ABSTRAK
Pusat Pengkajian dan Perekayasaan Teknologi Kelautan dan Perikanan (P3TKP) - KKP telah mengembangkan perangkat keras elektronik log book penangkapan ikan (ELPI) berbasis GPRS, dengan fungsi utama untuk input data tangkapan ikan secara elektronik. Alat ini juga dilengkapi dengan fitur rekam jejak kapal yang diprogram untuk mengirimkan data posisi koordinat setiap periode tertentu secara otomatis. Data rekam jejak kapal ini dapat diintegrasikan dengan sistem pemantauan kapal perikanan atau VMS yang dikelola oleh Direktorat Jenderal PSDKP KKP. Penelitian ini bertujuan untuk mengintegrasikan sistem ELPI dengan sistem VMS offline. Penelitian ini terdiri dari beberapa tahap, yaitu perancangan perangkat lunak pada ELPI untuk mencatat rekam jejak kapal secara otomatis setiap 30 menit, perancangan perangkat lunak untuk integrasi sistem ELPI dengan VMS, serta pengujian di lapangan. Uji coba pengiriman data ELPI dibagi ke dalam dua server yaitu server P3TKP dan server VMS offline yang ada di PSDKP. Pada uji coba, data posisi koordinat berhasil terkirim ke server P3TKP dan server PSDKP setiap 30 menit secara otomatis, di mana data rekam jejak kapal tersebut dapat terlihat pada peta yang berada di perairan selatan Jawa Barat. Dengan terintegrasinya kedua sistem ini diharapkan dapat memperkuat pengumpulan data posisi kapal ikan khususnya kapal di bawah ukuran 30 GT.
\end{abstract}

Kata kunci: ELPI, VMS, integrasi, rekam jejak kapal, kapal perikanan

\section{ABSTRACT}

Research and Development Centre for Marine and Fisheries (P3TKP) - KKP has developed hardware of electronic fishing log book (ELPI) with the primary function for input the catch fish data electronically. It is also equipped with vessel tracking feature programmed to submit coordinate position data any definite period automatically. This vessel tracking data can be integrated with the Vessel Monitoring Systems run by the Directorate General of PSDKP - KKP. This research is aimed at integrating ELPI with the offline system of VMS. Research is composed of several stages, namely design software on recordings ELPI for noting ship automatically every 30 minutes, to design software systems integration ELPI with VMS, and testing in the field. Trial data transmission ELPI is divided into two servers namely server P3TKP and server VMS offline in PSDKP. On trial, data position coordinate successfully sent to server P3TKP and server PSDKP every 30 minutes automatically, on which the vessel tracking data of it can be seen on a map of the sea in the southern West Java. With the integration of these two systems is expected to strengthen collection the vessel fishing position data especially under capacity of 30 GT.

Keywords: ELPI, VMS, integration, vessel tracking, fishing vessel

\section{PENDAHULUAN}

Untuk mendukung kebijakan pengelolaan sumber daya perikanan yang berkelanjutan, diperlukan data perikanan yang akurat terkait dengan kegiatan penangkapan ikan. Salah satu cara untuk memperoleh data penangkapan ikan yang akurat adalah menggunakan log book harian penangkapan ikan yang disyaratkan Direktorat Jenderal Perikanan Tangkap (DJPT), Kementerian Kelautan 
dan Perikanan (KKP). Penggunaan log book penangkapan ikan selama ini dilakukan secara manual dengan menggunakan kertas. Hal ini banyak mengalami kendala seperti data yang diisi tidak lengkap / kurang valid / tidak masuk akal, kesadaran pelaku usaha penangkapan ikan masih rendah, kesulitan dalam pengisian form log book karena banyaknya data yang harus diisikan (Marzuki, 2011).

Untuk mengatasi kendala tersebut, maka Pusat Pengkajian dan Perekayasaan Teknologi Kelautan dan Perikanan (P3TKP), Badan Penelitian dan Pengembanagn Kelautan dan Perikanan (Balitbang KP), KKP berhasil mengembangkan perangkat Elektronik Log Book Penangkapan Ikan (ELPI) berbasis GPRS (General Packet Radio Service). ELPI merupakan perangkat keras elektronik dengan jumlah kolom yang diisikan lebih sedikit sehingga proses input menjadi lebih mudah, cepat, dan akurat.

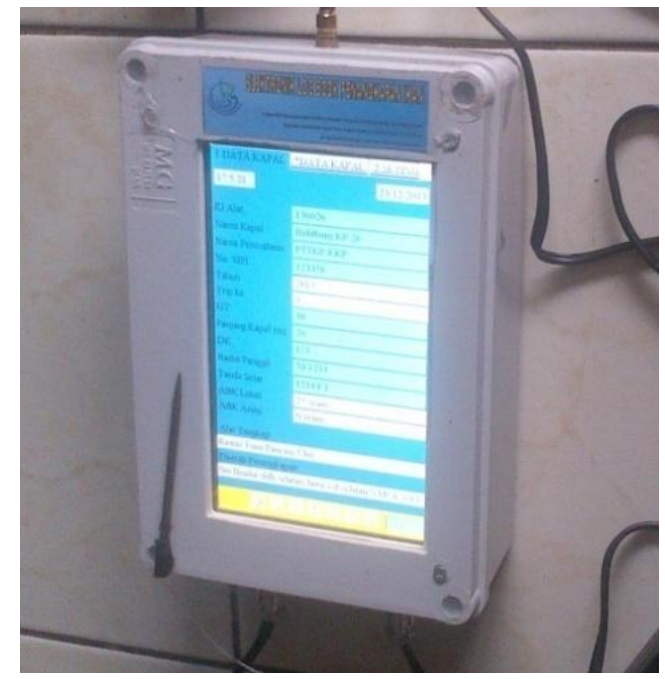

Gambar 1. Perangkat keras ELPI

Figure 1. The ELPI hardware

Namun, teknologi GPRS memiliki kelemahan terkait dengan jarak jangkauan sinyalnya, yaitu hanya sekitar 5-10 mil saja dari pantai (Marzuki, 2011).

Gambar 1 memperlihatkan foto perangkat keras ELPI. Perangkat keras ELPI tersebut berukuran panjang $23 \mathrm{~cm}$, lebar $15 \mathrm{~cm}$, dan tebal $7 \mathrm{~cm}$. Bagian utama alat ini adalah LCD (Liquid Crystal Display) layar sentuh berukuran 7 inch untuk melakukan input data dan menampilkan tulisan, antena GPS (Global Positioning System), serta adaptor. Alat ini juga dilengkapi dengan sensor oseanografi berupa sensor suhu, yang dapat dipasang jika akan digunakan untuk mengukur suhu permukaan laut.

Selain data tangkapan ikan, alat ini juga dilengkapi dengan fitur rekam jejak kapal (vessel tracking). Fitur ini dibuat agar ELPI bisa mengirimkan data koordinat kapal setiap periode tertentu secara otomatis. Pengaturan periode pengiriman data posisi tersebut dapat diatur sesuai dengan kebutuhan. Fitur rekam jejak kapal pada ELPI memiliki beberapa fungsi, yaitu:

- Mengetahui pergerakan kapal dari berangkat hingga mendarat kembali di pelabuhan.

- Dapat digunakan sebagai validasi data lokasi penangkapan ikan yang diinputkan melalui ELPI.

Hasil data rekam jejak kapal dengan ELPI selanjutnya dapat diintegrasikan dengan sistem VMS (Vessel Monitoring System) yang dikelola oleh Direktorat Jenderal Pengawasan Sumber Daya Kelautan dan Perikanan (Ditjen PSDKP) - KKP.

VMS atau sistem pemantauan kapal perikanan merupakan salah satu bentuk sistem pemantauan untuk mendukung pengawasan di bidang penangkapan dan atau pengangkutan ikan, dengan menggunakan satelit dan peralatan pemancar (transmitter) VMS yang ditempatkan pada kapal perikanan guna mempermudah pengawasan dan pemantauan terhadap kegiatan / aktivitas kapal perikanan (Direktorat Jenderal Pengawasan Sumber Daya Kelautan dan Perikanan, 2012).

Teknologi VMS, khususnya yang berbasis satelit terdiri dari tiga komponen penting (Gallagher, 2002), yaitu:

1. Sebuah transmitter atau transceiver yang dipasang di kapal perikanan untuk menunjukkan posisi kapal.

2. Media atau sistem transmisi sebagai wahana untuk mentransmisikan informasi posisi kapal dari kapal perikanan ke Fisheries Monitoring Center (FMC).

3. Fisheries Monitoring Center (FMC) atau pusat pemantauan untuk menerima, menyimpan, menampilkan, dan mendistribusikan data. 
Prinsip kerja VMS secara umum diawali dari transmitter yang mengirimkan data posisi kapal setiap periode tertentu melalui sistem satelit.

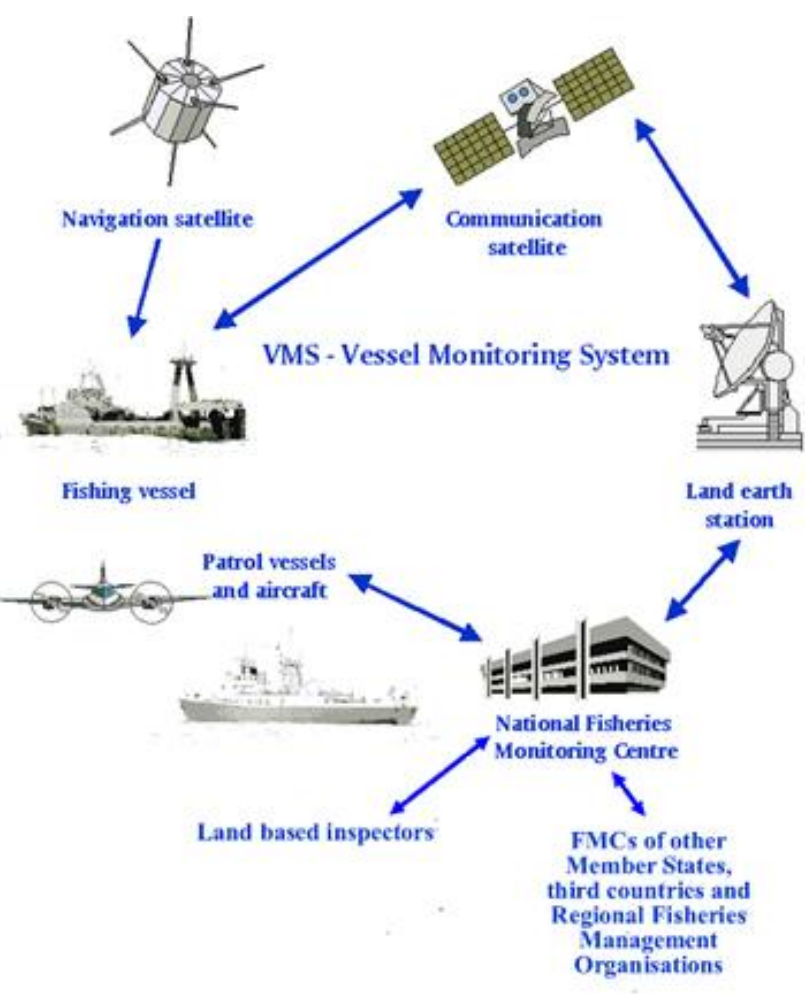

Gambar 2. Prinsip kerja VMS

Figure 2. VMS working mechanism

Sumber:

http://ec.europa.eu/fisheries/cfp/control/technologies/vm s/index_en.htm

Satelit ini akan menerima pesan dari kapal dan mengirimkan ke pusat pengolahan data satelit,dan kemudian data posisi kapal yang telah diolah disampaikan ke FMC (Kusuma, 2009). Jika ada indikasi terjadi IUU Fishing, maka FMC akan menghubungi pihak patroli untuk dilakukan penindakan. Prinsip kerja VMS dapat dilihat pada Gambar 2.

Di Indonesia, VMS telah diterapkan penggunaannya mulai tahun 2003 dan telah dikembangkan beberapa kali. Untuk mengimplementasikan VMS, di Kantor Pusat KKP di Jakarta telah dibangun Fishing Monitoring Center (FMC), serta dilakukan pemasangan transmiter VMS pada kapal-kapal perikanan. Hingga akhir tahun 2011, tercatat \pm 4201 unit transmitter VMS online terpasang dengan rata-rata keaktifan 2122 unit, dan 1500 unit transmitter VMS offline terpasang dengan rata-rata keaktifan
970 unit. Data VMS yang diperoleh dapat digunakan untuk menganalisis tingkat kepatuhan kapal penangkap ikan dan kapal pengangkut ikan Indonesia terhadap ketentuan mengenai wilayah penangkapan, alat dan metoda penangkapan, pendaratan hasil tangkapan, dan lain sebagainya. (Republik Indonesia, 2012).

Operasionalisasi dan penyelenggaraan VMS untuk kapal perikanan saat ini diatur dengan Peraturan Menteri Kelautan dan Perikanan Nomor 10/PERMEN-KP/2013 tentang Sistem Pemantauan Kapal Perikanan. Peraturan menteri tersebut mewajibkan kapal perikanan berukuran di atas 30 GT yang beroperasi di perairan Indonesia atau di laut lepas wajib memasang transmitter VMS online dengan pengiriman data posisi kapal tiap 1 (satu) jam secara terus-menerus.

Sebelum berlakunya Peraturan Menteri Kelautan dan Perikanan Nomor 10/PERMEN-KP/2013, penyelenggaraan VMS di Indonesia diatur dengan Peraturan Menteri Kelautan dan Perikanan Nomor PER.5/MEN/2007. Berdasarkan peraturan menteri tersebut, model VMS perikanan yang ada terdiri dari 2 jenis, yaitu VMS online yang diwajibkan untuk kapal perikanan berukuran di atas 60 GT dan VMS offline yang diwajibkan untuk kapal perikanan berukuran 30 - 60 GT. Pada VMS offline, pengiriman data menggunakan teknologi GPRS, yang akan mengirimkan data rekam jejak kapal perikanan bila mendapatkan sinyal GPRS. Bila tidak mendapat sinyal GPRS, data akan otomatis disimpan di data logger perangkat transmitter VMS dan akan dikirimkan secara otomatis ke server VMS offline bila terdapat sinyal GPRS.

Sistem rekam jejak kapal memungkinkan saling bersinerginya antara VMS offline dan ELPI dalam mencatat data posisi kapal perikanan selama beroperasi di tengah laut. Penelitian ini bertujuan untuk mengintegrasikan sistem ELPI dengan sistem VMS offline yang dikelola Ditjen PSDKP. Dengan adanya integrasi ini, diharapkan dapat diperoleh data yang lengkap berupa data penangkapan ikan dan data posisi kapal perikanan, sehingga dapat digunakan untuk mengelola sumber daya perikanan yang berkelanjutan. 


\section{BAHAN DAN METODE}

Penelitian ini terdiri dari beberapa tahap, yaitu:

1. Perancangan perangkat lunak untuk mencatat rekam jejak kapal.

2. Perancangan perangkat lunak untuk integrasi sistem ELPI dengan VMS

3. Pengujian di lapangan

\subsection{Perancangan Perangkat Lunak untuk Mencatat Rekam Jejak Kapal Secara Otomatis}

Pada tahap ini, dilakukan perancangan perangkat lunak pada ELPI untuk mencatat rekam jejak kapal yang bisa di-setting akan mengirim data setiap 30 menit sekali secara otomatis. Data rekam jejak kapal tersebut berisikan: waktu, posisi koordinat, kecepatan kapal, dan arah kapal (heading). Langkah-langkah dalam proses perancangan ini ditunjukkan pada Gambar 3. Perancangan perangkat lunak ini menggunakan bahasa pemrograman C++ untuk Qt framework.

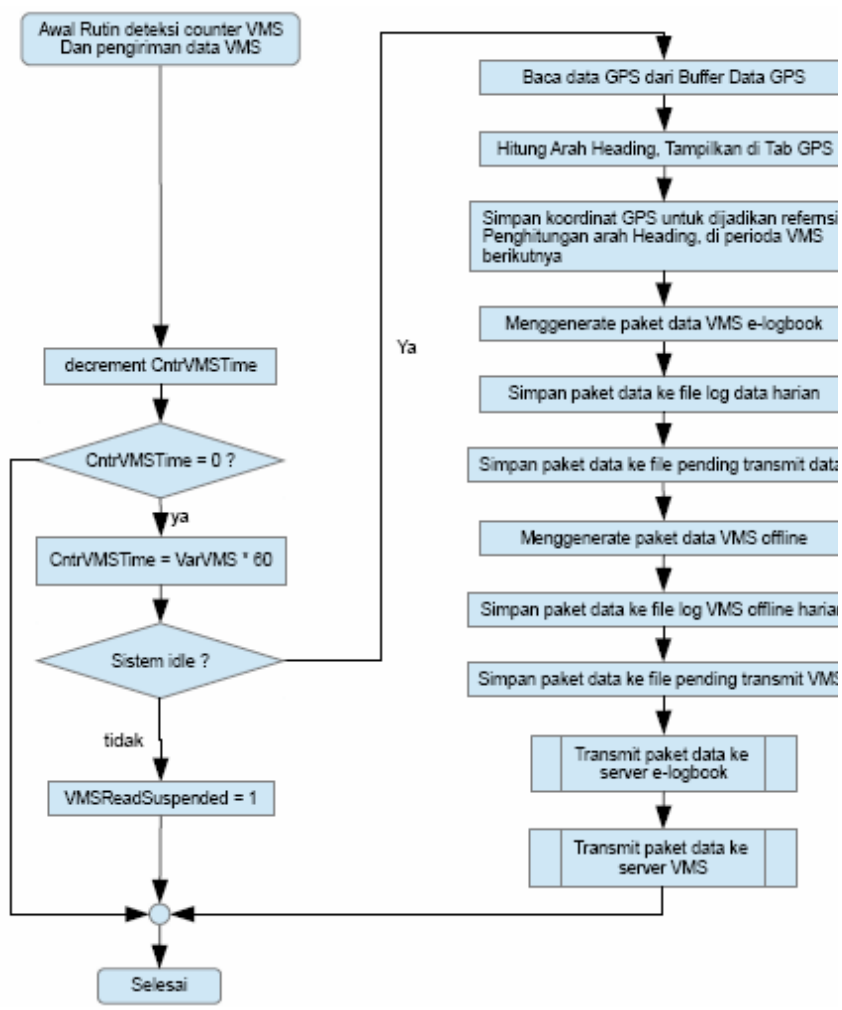

Gambar 3. Diagram alir rutin pengiriman paket data VMS

Figure3. Flowchart of VMS data transmission
Proses diawali dengan pembacaan data koordinat dari sensor GPS, kemudian dilakukan perhitungan arah heading kapal. Data koordinat GPS tersebut kemudian dijadikan referensi penghitungan arah heading kapal di periode VMS berikutnya. Kemudian dilakukan pembangkitan paket data VMS. Paket data VMS tersebut kemudian disimpan di file $\log$ data harian dan file pending transmit data. Paket data VMS tersebut kemudian dikirim ke server ELPI dan server VMS di PSDKP.

\subsection{Perancangan Perangkat Lunak untuk Integrasi Sistem ELPI dengan VMS}

Pada proses ini, dilakukan perancangan agar data rekam jejak kapal dari perangkat ELPI dapat terkirim dan ditampilkan di web server VMS di PSDKP. Web server PSDKP dapat menerima dan membaca data tersebut, lalu menampilkan data tersebut di situs web PSDKP. Langkah-langkah dalam proses perancangan ini ditunjukkan pada Gambar 4.

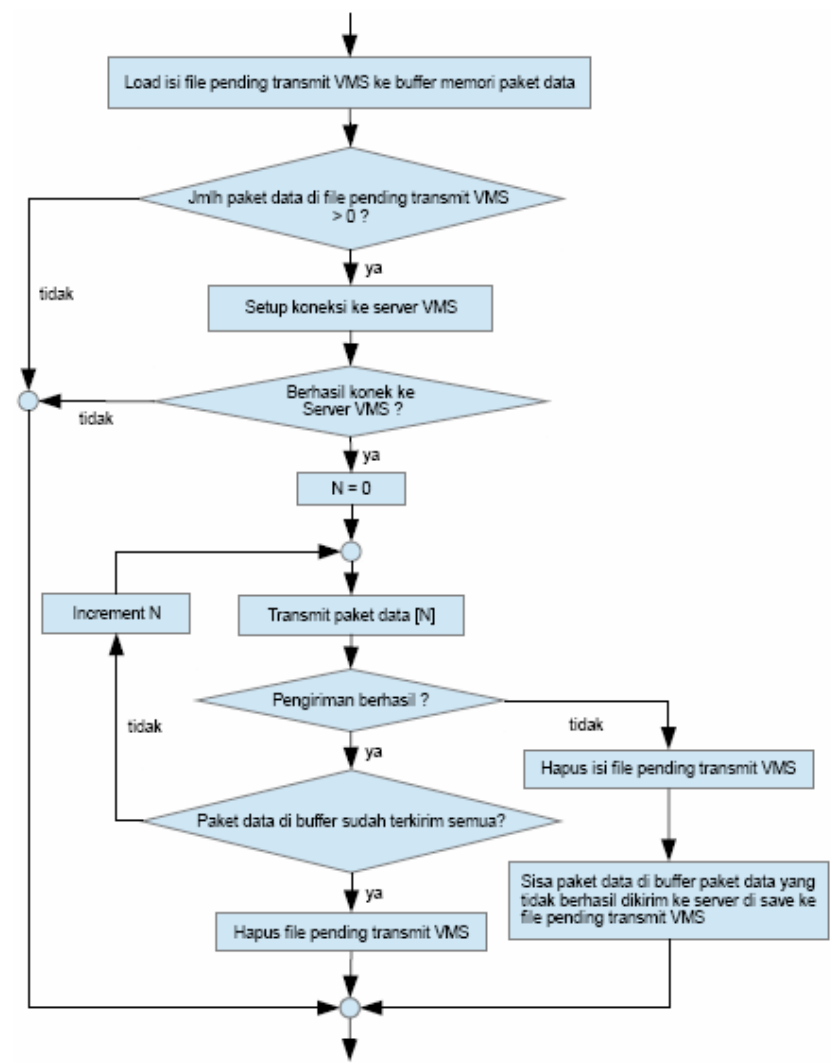

Gambar 4. Diagram alir rutin pengiriman paket data ke server VMS - PSDKP

Figure4. Flowchart of data transmission to VMS PSDKP server 
Langkah-langkah pada Gambar 4 dapat dijelaskan sebagai berikut. Isi file pending transmit VMS akan disimpan ke buffer memori paket data. Perangkat ELPI akan melakukan setup koneksi ke server VMS di PSDKP. Setelah berhasil melakukan koneksi dengan server VMS di PSDKP, paket data VMS kemudian dikirim ke server tersebut. Paket data VMS tersebut kemudian diterima di server PSDKP untuk kemudian ditampilkan di situs web PSDKP.

Agar paket data VMS dari ELPI bisa diterima oleh server PSDKP, maka format data pada ELPI yang dikirim ke server PSDKP harus sesuai dengan format data server PSDKP. Format data tersebut adalah sebagai berikut.

GPRMC,IDOffline,hhmmss,A_atau_V,Lon gitude,N_atau_S,Latitude,E_atau_W,Speed String,HeadingString,ddmmyy, 0,0000

Setiap data dipisahkan dengan tanda koma. Arti format data tersebut adalah sebagai berikut:

- GPRMC merupakan informasi minimal yang direkomendasikan untuk pelacakan.

- ID offline merupakan nomor identitas perangkat transmitter VMS yang diberikan oleh Ditjen PSDKP.

- hhmmss merupakan data jam, menit, detik saat perangkat mengirim data.

- A_atau_V merupakan kode status data, A artinya data valid, $\mathrm{V}$ artinya data invalid.

- Longitude merupakan data koordinat lintang.

- N_atau_S merupakan nama lintang, jika N berarti lintang utara, jika $\mathrm{S}$ berarti lintang selatan.

- Latitude merupakan data koordinat bujur.

- E_atau_W merupakan nama bujur, jika E berarti bujur timur, jika W berarti bujur barat.

- SpeedString merupakan data kecepatan kapal dalam satuan knots.

- HeadingString merupakan data arah (heading) kapal dalam satuan derajat.

- ddmmyy merupakan data hari, bulan, tahun saat perangkat mengirim data.

- 0,,0000 menunjukkan checksum.

\subsection{Pengujian}

Pengujian ELPI dilakukan di PPN Palabuhanratu, Kabupaten Sukabumi, Jawa Barat. Prosedur pengujian yang dilakukan adalah sebagai berikut:

- Peralatan ELPI dipasang di atas kapal perikanan
- Pengujian ini menggunakan alat ELPI dengan ID 130013

- Kapal melakukan pelayaran ke tengah laut hingga alat tidak memperoleh sinyal GPRS

- ELPI akan mengirimkan data posisi kapal, arah/heading, dan kecepatan kapal tiap 30 menit secara otomatis.

- Selama tidak terkoneksi dengan GPRS, data akan tersimpan di dalam data logger ELPI.

- Pemantauan rekam jejak kapal dapat dilakukan melalui web http://167.205.110.252/e-logbook yang disediakan P3TKP.

- Pemantauan rekam jejak kapal juga dapat dilakukan melalui web FMC PSDKP: http://vmsoffline.psdkp.kkp.go.id.

- Analisis data rekam jejak kapal dapat dilakukan dengan memplotkan data posisi rekam jejak kapal ke dalam peta

- Validasi dilakukan dengan menganalisis data rekam jejak kapal yang ada di web P3TKP dan Pusdal PSDKP

\section{HASIL DAN PEMBAHASAN}

Hasil pengujian yang dilakukan pada kapal perikanan yang terpasang ELPI menunjukkan adanya jalur lintasan keberadaan kapal sesuai dengan koordinat GPS. Untuk membedakan jalur lintasan tiap kapal yang tercatat, maka setiap kapal yang terpasang ELPI diberikan nomor ID kapal pada saat registrasi awal. Data ID kapal tersebut akan terlihat pada webserver.

Gambar 5 memperlihatkan tampilan data posisi koordinat alat yang diuji coba pada kapal perikanan yang berpangkalan di PPN Palabuhan Ratu. Data rekam jejak kapal tersebut merupakan contoh sebagian data rekam jejak kapal yang diterima di sisi server P3TKP, serta ditampilkan dengan bantuan aplikasi Googlemap. Data rekam jejak kapal tersebut terlihat di perairan Samudra Hindia bagian selatan Jawa Barat.

Gambar 6 memperlihatkan tampilan data posisi koordinat alat yang diuji coba di salah satu kapal perikanan yang berpangkalan di PPN Palabuhan Ratu dan diterima di sisi server PSDKP. Data rekam jejak kapal tersebut terlihat dari perairan Samudra Hindia ke PPN Pelabuhan Ratu. 


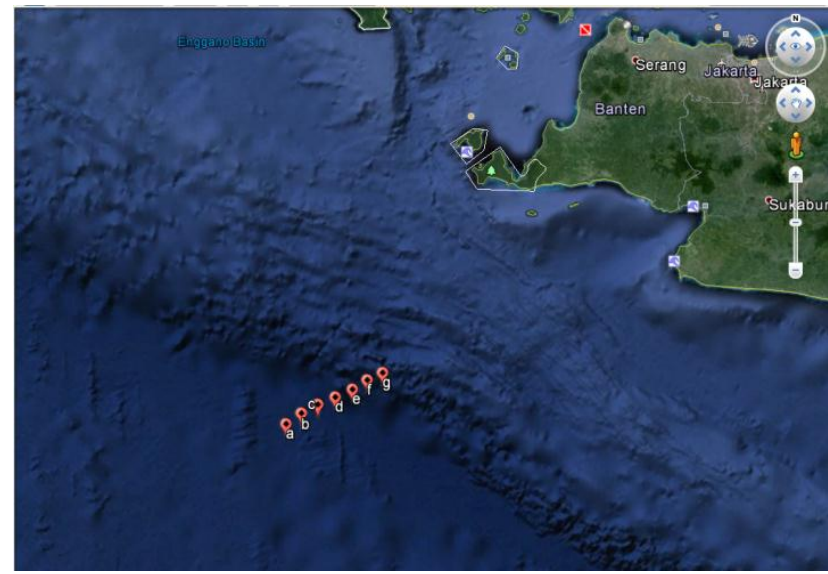

Gambar 5. Tampilan data rekam jejak kapal selama uji coba ELPI dilihat dengan Googlemap

Figure5. Display of vessel tracking data during the trial ELPI seen with Googlemap
Data rekam jejak kapal pada Gambar 6 terlihat memiliki pola yang sama dengan data rekam jejak kapal pada Gambar 5. Hal ini membuktikan data yang diterima di sisi server P3TKP dan server PSDKP berasal dari sumber yang sama yaitu data koordinat yang dikirim oleh alat ELPI.

Gambar 7 dan Gambar 8 memperlihatkan data yang dikirimkan selama pengujian di lapangan. Data yang ditandai garis warna merah pada Gambar 7 dan Gambar 8 memperlihatkan data waktu dan koordinat yang diterima database server P3TKP selama uji coba. Gambar 7 merupakan tampilan data mentah yang dikirim dari ELPI ke web server P3TKP. Data mentah tersebut memiliki format dan kode tententu.

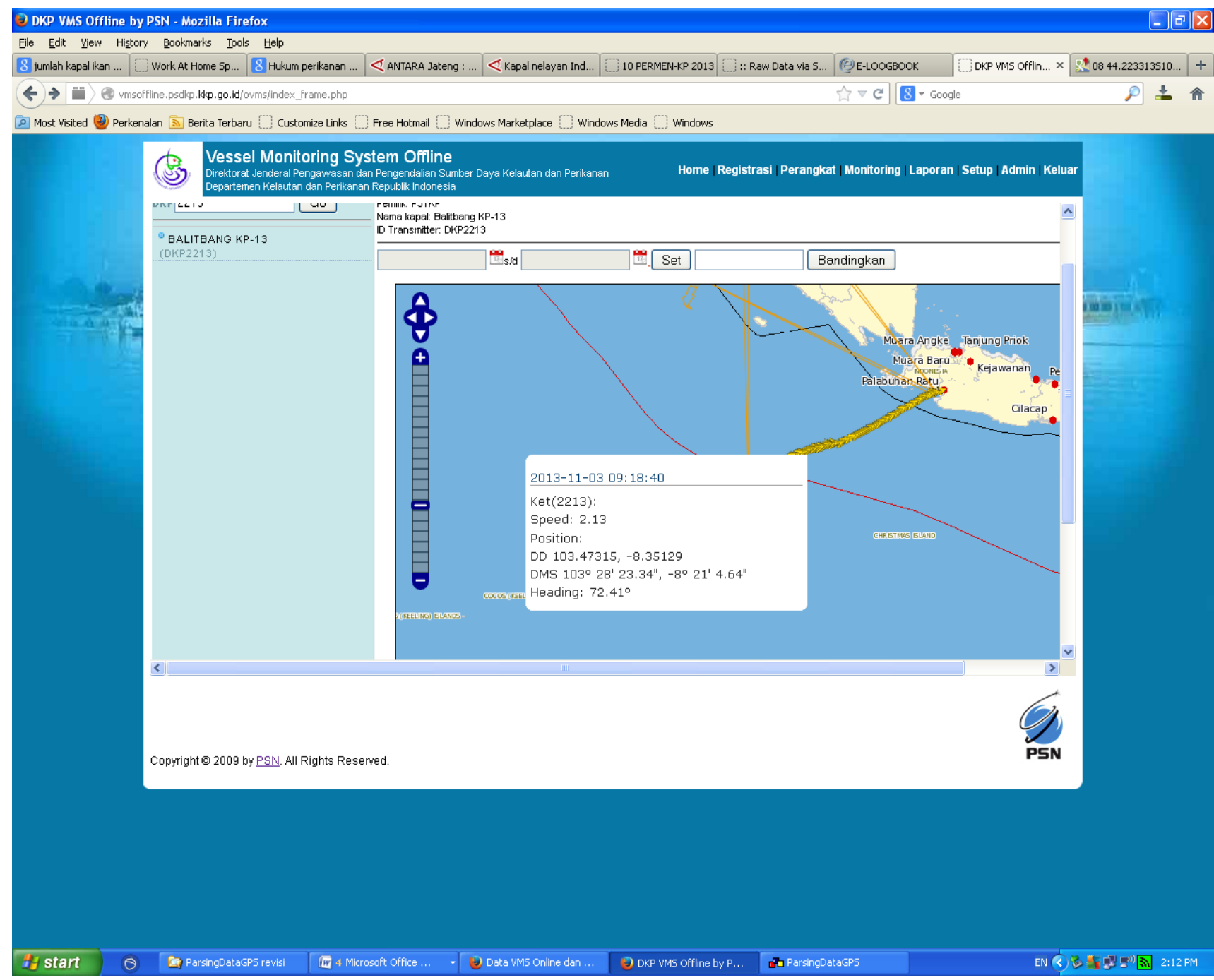

Gambar 6. Tampilan data rekam jejak kapal di server PSDKP

Figure 6. Display of vessel tracking data in PSDKP server 


\begin{tabular}{|c|c|c|c|c|}
\hline 2013-11-04 & 14:38:58 & 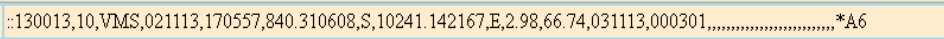 & I & \\
\hline 2013-11-04 & $14: 38: 52$ & 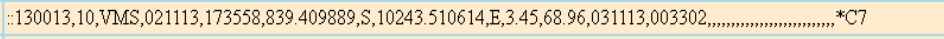 & I & \\
\hline 2013-11-04 & $14: 38: 46$ & 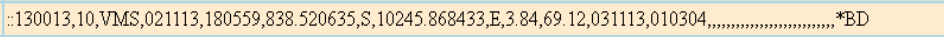 & I & \\
\hline 2013-11-04 & 14:38:40 & 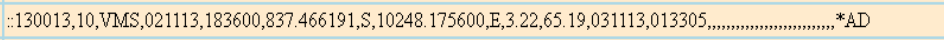 & I & \\
\hline 2013-11-04 & 14:38:28 & $\because 130013,10, \mathrm{VMS}, 021113,193602,834.906099, \mathrm{~S}, 10252.927156, \mathrm{E}, 2.95,60.80,031113,023308, \ldots, \ldots, \ldots, \ldots, \ldots, \ldots, \ldots, \ldots, \ldots,,{ }^{*} \mathrm{BF}$ & I & \\
\hline 2013-11-04 & 14:38:22 & 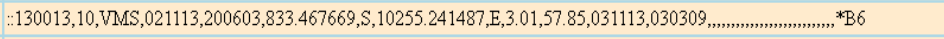 & I & \\
\hline 2013-11-04 & 14:38:04 & 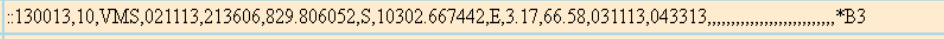 & I & \\
\hline 2013-11-04 & $14: 37: 58$ & 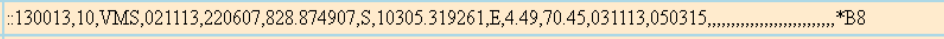 & I & \\
\hline 2013-11-04 & $14: 37: 52$ & $\because 130013,10, \mathrm{VMS}, 021113,224832,827.348861, \mathrm{~S}, 10308.973294, \mathrm{E}, 3.74,66.92,031113,054504, \ldots, \ldots, \ldots, \ldots, \ldots, \ldots, \ldots, \ldots, \ldots, \ldots, \ldots{ }^{*} \mathrm{CD}$ & I & \\
\hline 2013-11-04 & $14: 37: 46$ & 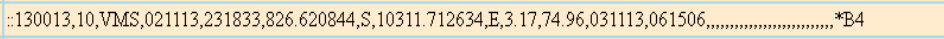 & I & \\
\hline 2013-11-04 & $14: 37: 40$ & 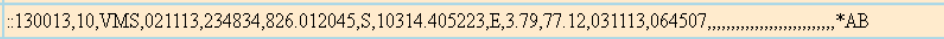 & I & \\
\hline 2013-11-04 & 14:37:10 & 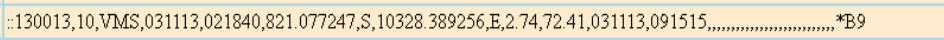 & I & \\
\hline 2013-11-04 & 14:37:04 & $\because 130013,10, \mathrm{VMS}, 031113,024841,820.087713, \mathrm{~S}, 10331.323605, \mathrm{E}, 3.00,71.18,031113,094516, \ldots, \ldots, \ldots, \ldots, \ldots, \ldots, \ldots, \ldots, \ldots, \ldots,{ }^{*} \mathrm{AA} 4$ & I & \\
\hline 2013-11-04 & $14: 36: 59$ & 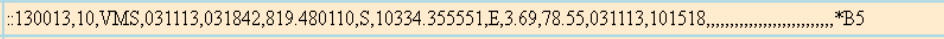 & I & \\
\hline 2013-11-04 & $14: 36: 53$ & 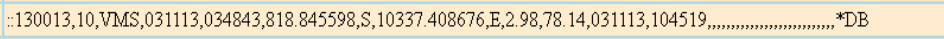 & I & \\
\hline 2013-11-04 & 14:36:47 & 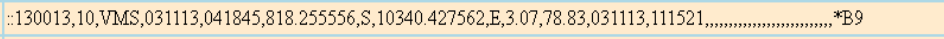 & I & \\
\hline 2013-11-04 & $14: 36: 41$ & 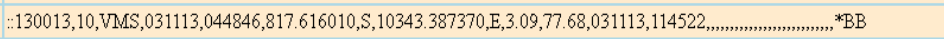 & I & \\
\hline 2013-11-04 & $14: 36: 35$ & 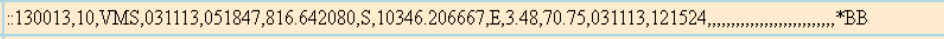 & I & \\
\hline 2013-11-04 & $14: 36: 29$ & 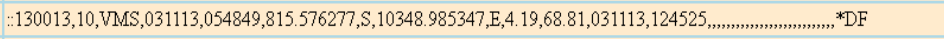 & I & \\
\hline 2013-11-04 & $14: 36: 23$ & 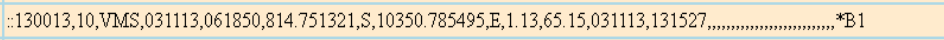 & I & \\
\hline 2013-11-04 & 14:36:17 & 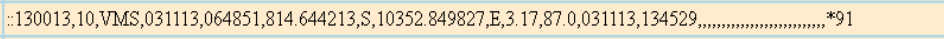 & I & \\
\hline 2013-11-04 & 14:36:12 & 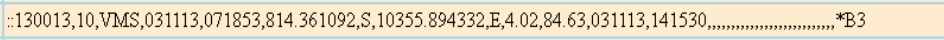 & I & \\
\hline
\end{tabular}

Gambar 7. Tampilan data mentah pengujian ELPI di PPN Palabuhan Ratu pada web server P3TKP Figure 7. Display of raw data from trial ELPI in PPN Palabuhan Ratu at P3TKP web server

\begin{tabular}{|c|c|c|c|c|c|c|c|}
\hline 521 & 130013 & $2013-11-0 / 10: 21: 05$ & $03-11-2013$ & $03: 48: 43$ & -8.3140933 & $103.6234 / / 93333$ & \# Map|\#\# Googlemap \\
\hline 522 & 130013 & 2013-11-07 10:21:05 & 03-11-2013 & 03:18:42 & -8.3246685 & 103.57259251667 & "\# Map | \#\# GoogleMap \\
\hline 523 & 130013 & 2013-11-07 10:21:05 & $03-11-2013$ & 02:48:41 & -8.3347952166667 & 103.52206008333 & \# Map |\#\# GoogleMap \\
\hline 524 & 130013 & 2013-11-07 10:21:05 & 03-11-2013 & 02:18:40 & -8.35128745 & 103.47315426667 & \#\# Map | \#\#: GoogleMap \\
\hline 525 & 130013 & 2013-11-07 10:21:05 & 03-11-2013 & 01:48:38 & -8.3659052166667 & 103.42655395 & \# Map | \#\# GoogleMap \\
\hline 526 & 130013 & 2013-11-07 10:21:05 & 03-11-2013 & 01:18:37 & -8.3841974333333 & 103.37969265 & \#ت Map | 曹 GoogleMap \\
\hline 527 & 130013 & 2013-11-07 10:21:05 & 03-11-2013 & $00: 48: 36$ & -8.4007907 & 103.33381351667 & \# Map |\# GoogleMap \\
\hline 528 & 130013 & 2013-11-07 10:21:05 & 03-11-2013 & 08:18:55 & -8.2382110166667 & 104.03139666667 & \#\# Map | \#\#\# GoogleMap \\
\hline 529 & 130013 & 2013-11-07 10:21:05 & 03-11-2013 & 08:48:57 & -8.23832235 & 104.0807207 & \#\# Map | \#\# GoogleMap \\
\hline 530 & 130013 & 2013-11-07 10:21:05 & 03-11-2013 & 16:19:18 & -7.89100505 & 104.78113188333 & \#\# Map | \#\# GoogleMap \\
\hline 531 & 130013 & 2013-11-07 10:21:05 & 03-11-2013 & 15:49:17 & -7.91603156666667 & 104.73303366667 & \# Map |\# GoogleMap \\
\hline 532 & 130013 & 2013-11-07 10:21:05 & 03-11-2013 & $15: 19: 15$ & -7.9391594 & 104.68434858333 & I\# Map | \#\# GoogleMap \\
\hline 533 & 130013 & 2013-11-07 10:21:05 & 03-11-2013 & 14:49:14 & -7.9615975 & 104.63678721667 & \#\# Map | \#\# GoogleMap \\
\hline 534 & 130013 & 2013-11-07 10:21:05 & 03-11-2013 & 14:19:12 & -7.9841919666667 & 104.5910204 & 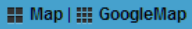 \\
\hline 535 & 130013 & 2013-11-07 10:21:05 & 03-11-2013 & 13:49:11 & -8.0074642 & 104.5449432 & "It Map | |\# GoogleMap \\
\hline 536 & 130013 & 2013-11-07 10:21:05 & 03-11-2013 & 13:19:09 & -8.0292003 & 104.49992578333 & \#\# Map | 汭 GoogleMap \\
\hline 537 & 130013 & 2013-11-07 10:21:05 & 03-11-2013 & 12:49:08 & -8.0520307166667 & 104.45407903333 & 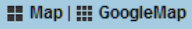 \\
\hline 538 & 130013 & 2013-11-07 10:21:05 & 03-11-2013 & 12:19:06 & -8.07557965 & 104.4070712 & \#\# Map | \#\# GoogleMap \\
\hline 539 & 130013 & 2013-11-07 10:21:05 & 03-11-2013 & 11:19:04 & -8.12062365 & 104.30666223333 & \# Map|\# GoogleMap \\
\hline 540 & 130013 & 2013-11-07 10:21:05 & 03-11-2013 & 11:19:04 & -8.12062365 & 104.30666223333 & 표 Map | \#\# GoogleMap \\
\hline 541 & 130013 & 2013-11-07 10:21:05 & 03-11-2013 & 10:49:02 & -8.1426650333333 & 104.2564229 & \# Map | \#\# GoogleMap \\
\hline 542 & 130013 & 2013-11-07 10:21:05 & 03-11-2013 & 10:19:01 & -8.1703416 & 104.20945246667 & \#\# Map | \#\# GoogleMap \\
\hline 543 & 130013 & 2013-11-07 10:21:05 & $03-11-2013$ & $09: 48: 59$ & -8198881 & 10416224638333 & \# Map | \#\# GoogleMap \\
\hline 544 & 130013 & 2013-11-07 10:21:05 & 03-11-2013 & 09:18:58 & -8.2270290166667 & 104.11624223333 & \#\# Map | 非 GoogleMap \\
\hline 545 & 130013 & $2013-11-0710: 21: 05$ & $03-11-2013$ & 00.18 .35 & -8.4181418 & 703.28666328333 & \# Map | \#\# GoogleMap \\
\hline
\end{tabular}

Gambar 8. Tampilan data pengujian ELPI di PPN Pelabuhan Ratu Figure 8. Display of trial ELPI data in PPN Palabuhan Ratu at P3TKP web server 
Sebagai contoh, pada data yang dilingkari garis merah tertulis data mentah sebagai berikut:

130013,10,VMS,031113,091858,813.621741,S,10 406.974534,E,3.77,72.19,031113,161537 *CB

Setiap data dipisahkan dengan koma. Arti data tersebut adalah sebagai berikut:

- 130013 adalah ID alat ELPI.

- 10 adalah kode bahwa paket data tersebut adalah data VMS.

- VMS adalah nama paket data tersebut.

- 031113 adalah data tanggal pengiriman data VMS, sumber data dari modul GPS, dengan format ddmmyy, dalam waktu GMT (Greenwich Mean Time). Jadi, 031113 berarti 3 November 2013 GMT.

- 091858 adalah data waktu pengiriman data VMS, sumber data dari modul GPS, dengan format hhmmss, dalam waktu GMT. Jadi, 091858 berarti pukul 09:18:58 GMT.

- 813.621741 adalah data koordinat lintang dalam format derajat dan menit (dddmm.mmmmmm). 813.621741 berarti 8 derajat lintang, 13,621741 detik.

- S adalah data nama lintang. Jika S berarti ada di lintang selatan, jika $\mathrm{N}$ berarti ada di lintang utara.

- 10406.974534 adalah data koordinat bujur dalam format derajat dan menit (dddmm.mmmmmm). 10406.974534 berarti 104 derajat bujur, 6,974534 detik.

- E adalah data nama bujur. Jika E berarti ada di bujur timur, jika W berarti ada di bujur barat.

- 3.77 adalah data kecepatan kapal dalam satuan knots.

- 72.19 adalah data arah/heading kapal dalam satuan derajat.

- 031113 adalah data tanggal pengiriman data VMS, sumber data dari RTC (Real Time Clock) pada modul layar sentuh ELPI, dengan format ddmmyy. Jadi, 031113 berarti 3 November 2013.

- 161537 adalah data waktu pengiriman data VMS, sumber data dari RTC (Real Time Clock) pada modul layar sentuh ELPI, dengan format hhmmss. Jadi, 161537 berarti pukul 16:15:37.

- *CB adalah kode paket data
Data mentah tersebut kemudian diolah di sisi server untuk dapat ditampilkan menjadi informasi yang berarti di situs web P3TKP.

Untuk koordinat, yang masih menggunakan format dddmm.mmmmmm akan dikonversi terlebih dahulu ke dalam format ddd.dddddd menggunakan rumus:

ddd.dddddd $=\mathrm{ddd}+(\mathrm{mm} \cdot \mathrm{mmmmmm}: 60)$

Hasilnya ditambah tanda minus (-) untuk lintang selatan dan bujur barat, serta tidak ditambah tanda minus (-) untuk lintang utara dan bujur timur.

Contoh perhitungan:

Data mentah dari GPS: 813.621741 S, maka konversi koordinat dalam format ddd.dddddd adalah:

$$
\begin{aligned}
\text { ddd.dddddd } & =\mathrm{ddd}+(\mathrm{mm} . \mathrm{mmmmmm}: 60) \\
& =8+(13,621741: 60) \\
& =8+0,2270290166667 \\
& =8,2270290166667 \\
& =8,22703 \text { (pembulatan) }
\end{aligned}
$$

Karena koordinat berada di lintang selatan, maka hasil konversi tersebut menjadi $-8,22703$.

Gambar 8 memperlihatkan data uji coba yang di terima di sisi web server P3TKP. Data tersebut terekam oleh ELPI dan disimpan di data logger pada tanggal 3 November 2013 dan dikirim ke server secara otomatis pada tanggal 7 November 2013. Data yang ditampilkan di web P3TKP tersebut masih menggunakan format waktu 0 GMT. Sebagai contoh, data yang dilingkari garis merah adalah:

- Tanggal data rekam jejak kapal: 3 November 2013

- Waktu: 09:18:58 GMT

- Koordinat lintang: $-8,2270290166667$

- Koordinat bujur: 104,11624223333

Selain ke web server P3TKP, data rekam jejak kapal juga terkirim ke web server VMS offline yang dikelola oleh Ditjen PSDKP-KKP. Hasilnya bisa dilihat pada Gambar 9.

Gambar 9 memperlihatkan data rekam jejak kapal yang dikirimkan ke server VMS offline PSDKP. 


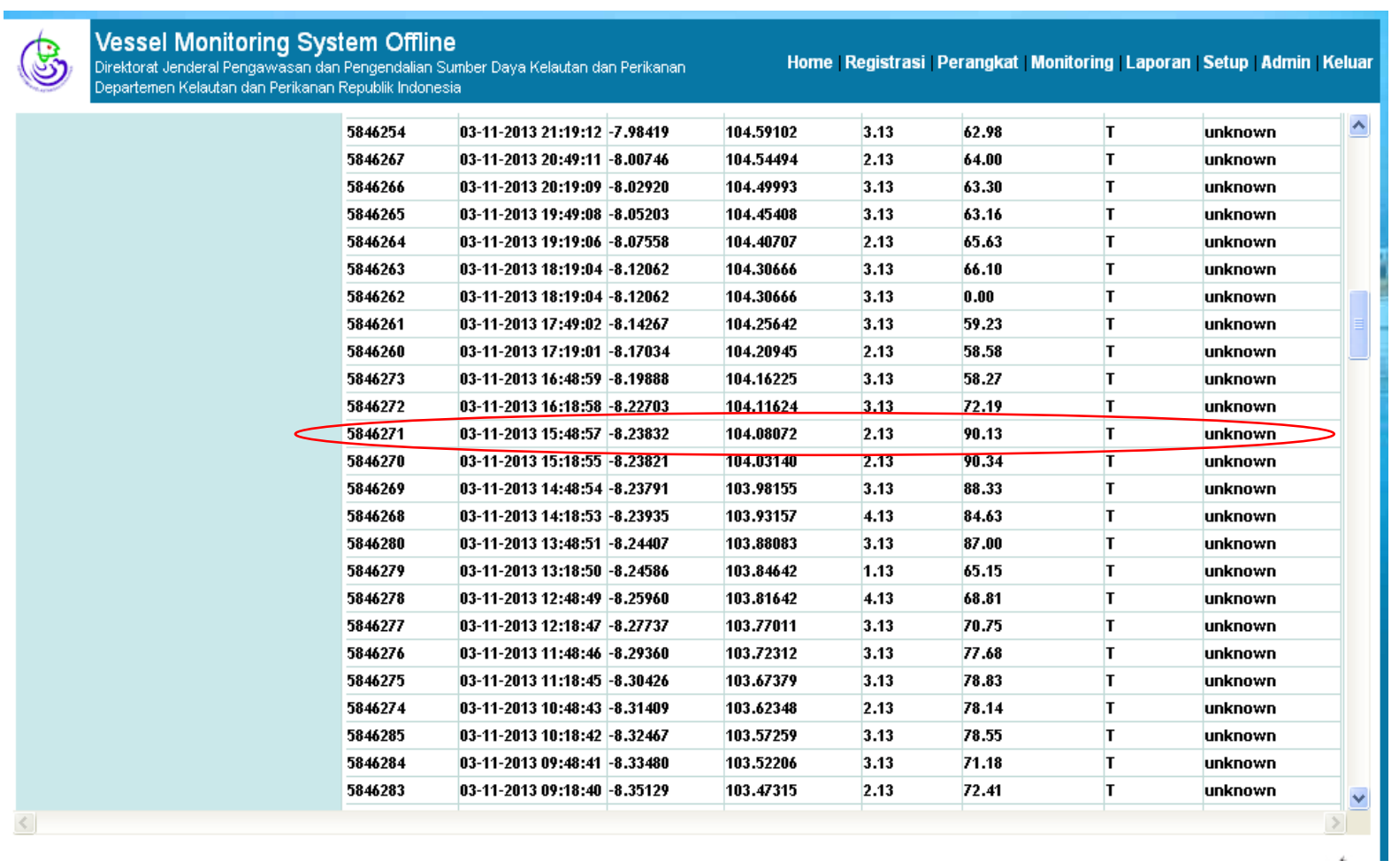

Gambar 9. Tampilan data ELPI di server PSDKP pada pengujian di PPN Palabuhan Ratu Figure 9. Display of ELPI data in PSDKP server from the trial at PPN Palabuhan Ratu

Data yang dikirimkan oleh alat ELPI ke web server PSDKP merupakan data yang juga dikirimkan ke server P3TKP yang ditunjukkan pada Gambar 7 dan Gambar 8. Terdapat perbedaan sedikit antara data yang ditampilkan di web P3TKP dan web PSDKP. Di web PSDKP, format waktu yang digunakan adalah +7 GMT (Waktu Indonesia Barat).

Selain itu, hasil konversi koordinat GPS dibulatkan 5 desimal. Sebagai contoh, data yang dilingkari garis merah adalah:

- Tanggal data rekam jejak kapal: 3 November 2013

- Waktu: 16:18:58 WIB

- Koordinat lintang: $-8,22703$

- Koordinat bujur: 104,11624

Keberhasilan integrasi data rekam jejak kapal dari ELPI ke dalam sistem VMS offline yang ada di PSDKP dapat diketahui dengan terlihatnya data yang dikirimkan oleh ELPI ke dalam sistem VMS offline melalui server yang ada.

Selain pengiriman data rekam jejak kapal, pengiriman data hasil tangkapan sesuai dengan daftar yang termuat dalam log book penangkapan ikan manual dilakukan melalui integrasi kedua server, yakni server P3TKP dan VMS yang ada di PSDKP. Hasil integrasi ini dapat digunakan untuk validasi data hasil penangkapan ikan, sehingga membantu proses pengelolaan sumber daya perikanan yang berkelanjutan.

Dengan terintegrasinya kedua sistem ini, diharapkan dapat memperkuat pengumpulan data rekam jejak kapal perikanan dengan data hasil tangkapan ikan, sehingga dapat membantu proses pengelolaan sumber daya perikanan yang berkelanjutan.

\section{KESIMPULAN}

1. Sistem ELPI selain berfungsi sebagai log book penangkapan ikan secara elektronik dapat berfungsi sekaligus untuk pemantauan kapal perikanan dengan mengintegrasikan ke dalam VMS yang dikelola Ditjen PSDKP.

2. Dengan proses integrasi tersebut, data rekam jejak kapal yang dihasilkan ELPI dapat ditampilkan di web server PSDKP.

3. Data yang ditampilkan di web P3TKP menggunakan format waktu 0 GMT, 
sedangkan data yang ditampilkan di web PSDKP menggunakan format waktu +7 GMT (Waktu Indonesia Barat).

4. Dengan terintegrasinya kedua sistem ini, diharapkan dapat memperkuat pengumpulan data rekam jejak kapal perikanan dengan data hasil tangkapan ikan, sehingga dapat membantu proses pengelolaan sumber daya perikanan yang berkelanjutan.

\section{UCAPAN TERIMA KASIH}

Ucapan terima kasih kami sampaikan kepada Pusat Pengkajian dan Perekayasaan Teknologi Kelautan dan Perikanan (P3TKP), Balitbang KP, KKP atas dukungan dananya sehingga penelitian ini dapat terselesaikan dengan baik, serta kepada Direktorat Pemantauan Sumber Daya Kelautan dan Perikanan dan Pengembangan Infrastruktur Pengawasan, Ditjen

PSDKP, KKP atas kerjasamanya dalam membantu proses integrasi ELPI dengan VMS.

\section{DAFTAR PUSTAKA}

Direktorat Jenderal Pengawasan Sumber Daya Kelautan dan Perikanan. (2012). Prosedur standar VMS online. Jakarta:Kementerian Kelautan dan Perikanan.

Gallaher, R. (2002). Fishing vessel monitoring: The what, why, and how. Paper presented in: Sub-Regional Fisheries Commission Workshop on Vessel Monitoring System. Saly, Senegal, 14-17 October 2002. ftp://ftp.fao.org/docrep/fao/005/y4447e/y444 7e01.pdf. Diakses 15 November 2013.

Kusuma, L.P.A.S.C. (2009). VMS dalam pengelolaan sumberdaya perikanan: Konsep dan penggunaannya. VMS dalam pengelolaan sumberdaya perikanan. Jakarta: Pusat Riset Teknologi Kelautan. Pp. 35-47.

Marzuki, M.I. (2011). Membangun elektronik logbook perikanan untuk menunjang pengelolaan sumber daya ikan yang berkelanjutan. Bunga rampai: Application of sustainable development technology in Indonesia. Jakarta: Pusat Pengkajian dan Perekayasaan Teknologi Kelautan dan Perikanan. Pp. 53-59.

Republik Indonesia. (2007). Peraturan Menteri Kelautan dan Perikanan nomor
PER.5/MEN/2007 tentang penyelenggaraan sistem pemantauan kapal perikanan. Jakarta.

Republik Indonesia. (2010). Peraturan Menteri Kelautan dan Perikanan nomor PER.18/MEN/2010 tentang log book penangkapan ikan. Jakarta.

Republik Indonesia. (2012). Keputusan Menteri Kelautan dan Perikanan nomor

PER.50/MEN/2012 tentang rencana aksi nasional pencegahan dan penanggulangan illegal, unreported, and unregulated fishing tahun 2012-2016. Jakarta.

Republik Indonesia. (2013). Peraturan Menteri Kelautan dan Perikanan Nomor 10/PERMEN-KP/2013 tentang sistem pemantauan kapal perikanan. Jakarta. 